\title{
Postoperative Problems Following Surgical Corrections for Spastic Equinovarus Deformities
}

\author{
Mikio Muraoka ${ }^{1,2 *}$, Koshiro Imai ${ }^{2}$, Shin Watanabe ${ }^{2}$ and Yasuharu Kinjo ${ }^{2}$ \\ ${ }^{1}$ Department of Rehabilitation Medicine, Kameda-Daiichi Hospital, Niigata, Japan \\ ${ }^{2}$ Department of Orthopedic Surgery, Kameda-Daiichi Hospital, Niigata, Japan \\ *Corresponding Author: Mikio Muraoka, Department of Rehabilitation Medicine, \\ Kameda-Daiichi Hospital, Niigata, Japan.
}

Received: February 07, 2022

Published: February 24, 2022

(C) All rights are reserved by Mikio Muraoka., et al.

\begin{abstract}
Objective: Surgical corrections are effective for severe spastic equinovarus deformities, but postoperative problems may occur over time. The present study examined postoperative problems and differentiated the proper surgical procedures.

Materials and Methods: We studied 12 feet of 11 patients with severe equinovarus deformities resulting from stroke or brain injury that were corrected surgically. Achilles tendons elongation after Z-plasty $(n=7)$ or fractional tendinous elongation $(n=5)$ was performed. Tendon transfers were performed using the tibialis anterior (TA) $(n=7)$ or tibialis posterior $(\mathrm{TP})(\mathrm{n}=5)$ tendon. Flexor hallucis longus (FHL), flexor digitorum longus (FDL), or flexor digitorum brevis (FDB) tendons were released or elongated for 9 feet with curling toes.

Results: Pes calcaneus deformities occurred postoperatively in 4 feet undergoing a combination of Achilles tendon Z-plasty and TP tendon transfer, and required revision surgery. Of the 9 feet with curling toes, 4 underwent flexor elongations for curling toes, and 3 of these required flexor tenotomies or additional elongations; 5 feet in which the flexor tendons were released required no further surgery.

Conclusion: Achilles tendon elongation following Z plasty often causes overcorrection of pes calcaneus when the transferred TP tendon works too strongly. In contrast, overcorrection does not seem to occur when fractional tendinous elongation of Achilles tendon and TA tendon transfer are combined. Surgeons should consider whether elongations for curling toes are appropriate to perform during the first surgery because subsequent operations are often required.

Keywords: Equinovarus; Curling Toe; Stroke; Brain Injury; Spasticity; Surgery
\end{abstract}

\section{Abbreviation}

FDB, flexor digitorum brevis; FDL, flexor digitorum longus; FHL, flexor hallucis longus; TA, Tibialis anterior; TP, tibialis posterior; EHL, extensor hallucis longus; EDL, extensor digitorum longus

\section{Introduction}

It has been reported that surgical corrections for severe equinovarus and curling toes* following stroke or brain injury are highly successful and adverse effects are rare. Tibialis anterior (TA), flexor hallucis longus (FHL), flexor digitorum longus (FDL), or tibialis posterior (TP) tendon transfers with Achilles tendon elonga- tion are recommended for equinovarus, and FHL, flexor digitorum longus (FDP), or flexor digitorum brevis (FDB) tendon elongations (tenotomies) are performed for curling toes (Figure 1) [1-4]. Postoperative problems, such as overcorrection of pes calcaneus and recurrence of curling toes over time (Figure 2), however, are not well discussed. Here, we examined postoperative problems and differentiated the proper surgical procedures.

${ }^{*}$ Curling toes are toes with excessive flexion, and are different from claw toes, which are associated with intrinsic muscle weakness.

\section{Materials and Methods}




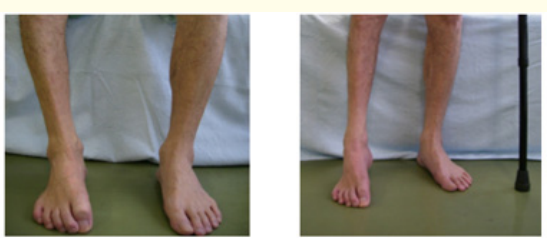

a: preoperative status
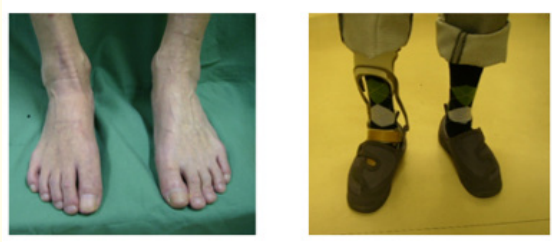

b: postoperative status

Figure 1: Surgical correction for spastic equinovarus deformity: Foot deformity was corrected and a stable gait with ankle foot orthosis was achieved.

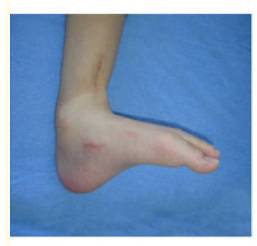

a: Pes calcaneus

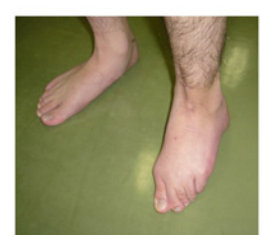

b: Pes valgus

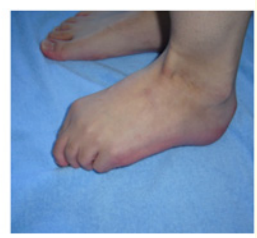

c: Curling toe
Figure 2: Postoperative problems: Pes calcaneus, Pes valgus, and curling toes may occur over the long-term, potentially causing pressure sores on the heel and corns on the toes.

We studied 12 feet of 11 patients with severe equinovarus deformities resulting from stroke $(n=8)$ or brain injury $(n=3)$ that were corrected surgically. In 1 patient with brain injury, consecutive reconstruction surgery was required bilaterally.

Of the 11 patients, 8 were men and 3 were women (age range 16 - 72 years). Hemiplegic lower limbs were classified according to the Brunnstrom stage; IV in 11 lower limbs and III in 1 lower limb [5]. Two patients were able to ambulate in the neighborhood using ankle foot orthoses and canes, 2 patients were able to ambulate in the home, 2 patients were nonfunctional (walk for exercise only), and 5 patients were non-ambulators [6]. The period from the onset to the surgical corrections was 5 months to 14 years. The followup period after surgery was 2 to 10 years (Table 1 ). Twelve surgical reconstructions were performed by combining Achilles tendon elongation and TA or TP tendon transfer for the equinovarus deformities. In 7 feet with more severe equinus deformity, Achilles tendons were elongated after Z-plasty, and in the remaining 5 feet, fractional tendinous elongations were performed (Figure 3) [7,8]. In 5 feet with severe hindfoot varus deformity, TP tendon transfers were performed through the interosseous membrane to the dorsum of the foot. In the remaining 7 feet, TA tendon transfers were performed after split anterior tibial tendon transfer (SPLATT) [1,9] for 5 feet, and after whole anterior tibial tendon transfer for 2 feet. The transferred TA or TP tendons were anchored to the cuboid or third cuneiform using suture anchors, interference screws, or bone tunnel fixation. Curling toes (excessive toe flexion) are common following stroke or brain injury, and in this study, 9 feet with curling toes were surgically corrected. Tenotomies of the FHL, FDL, or FDB were performed in the sole of the foot for 5 feet, and tendinous elongations of FHL and FDL were performed in the remaining 4 feet after fractional elongation or Z-plasty proximal to the flexor retinaculum at the medial ankle (Table 2, Figure 3 ).

\section{Results}

Of the 11 patients that underwent surgery, 6 progressed in walking ability level, and the remaining 5 patients remained at the same level but showed improvement in locomotor activity and activities of daily living. Seven patients were able to walk independently in the home or neighborhood, whereas 4 patients remained nonfunctional or non-ambulatory. In 1 patient that remained non-ambulatory, transfers became easier. Pes calcaneus (calcaneo valgus) deformities occurred in 4 feet when a combination with Achilles tendon Z-plasty combined with TP tendon transfer was performed, and all required revision surgery for TP elongation between 8 months to 9 years. None of the 7 feet that underwent TA tendon transfer showed pes calcaneus deformity, but required ankle foot orthoses due to insufficient toe clearance. Of the 4 feet that underwent flexor elongations for curling toes, 3 feet required additional surgical procedures from 6 months to 2 years, while 5 feet that underwent flexor tenotomies required no further surgeries. In transferred tendon fixation, detachment problems occurred in 2 feet in which the tendon was anchored to the cuboid using su- 
Postoperative Problems Following Surgical Corrections for Spastic Equinovarus Deformities

119

\begin{tabular}{|c|c|c|c|c|c|c|c|}
\hline Case & Disease & Sex & Age & Br. Stage(L/E) & Walking ability & Period to surgery & F/U period \\
\hline \multirow{2}{*}{1} & \multirow{2}{*}{ Brain Injury } & \multirow{2}{*}{ M } & \multirow{2}{*}{23} & IV & Non-ambulation & (Rt) $2 y$ & $10 y$ \\
\hline & & & & IV & Non-ambulation & $(\mathrm{Lt}) 2 \mathrm{y}$ & $9 y$ \\
\hline 2 & C. Infarction & M & 72 & IV & Household & (Lt) $4 y$ & $3 y$ \\
\hline 3 & C. Hemorrhage & M & 16 & IV & Non-ambulation & (Lt) $5 \mathrm{~m}$ & $7 y$ \\
\hline 4 & Brain Injury & M & 16 & IV & Non-ambulation & (Lt) $7 \mathrm{~m}$ & $6 y$ \\
\hline 5 & Brain Injury & M & 25 & IV & Non-ambulation & (Rt) $8 y$ & $4 y$ \\
\hline 6 & C. Hemorrhage & $\mathrm{F}$ & 61 & IV & Nonfunctional & (Lt) $5 y$ & $4 y$ \\
\hline 7 & C. Hemorrhage & M & 62 & IV & Neighborhood & (Rt) $8 \mathrm{y}$ & $3 y$ \\
\hline 8 & C. Hemorrhage & M & 69 & IV & Nonfunctional & (Lt) $14 y$ & $3 y$ \\
\hline 9 & C. Hemorrhage & $\mathrm{F}$ & 59 & III & Non-ambulation & $(\mathrm{Lt}) 1 \mathrm{y}$ & $2 y$ \\
\hline 10 & C. Hemorrhage & M & 19 & IV & Household & (Lt) $7 y$ & $5 y$ \\
\hline 11 & C. Hemorrhage & $\mathrm{F}$ & 62 & IV & Neighborhood & (Rt) $5 y$ & $2 y$ \\
\hline
\end{tabular}

Table 1: Patients underwent corrective surgeries for spastic equinovarus deformities.

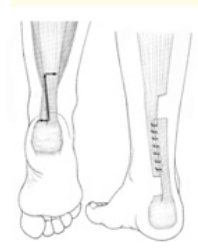

a: Z-plasty

(Achilles tendon)

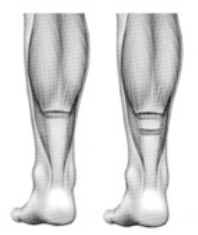

b: Fractional elongation (Gastrocnemius)

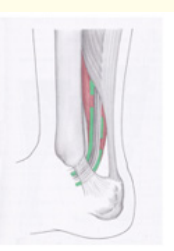

c: Fractional elongation (FHL and FDL)

Figure 3: Surgical procedures: Z-plasty, fractional elongation of the gastrocnemius, and fractional elongation of the FHL/FDL. Images were reproduced with permission from $[7,8]$.

ture anchors, and revision surgeries were required (Table 3).

In case 1 , bilateral severe pes calcaneus and curling toes became prominent with ankle dorsiflexion contracture 9 years after surgery, and the following revision surgeries were required: elongation of the transferred TP, TA, EHL, EDL, and peroneus tertius with FHL and FDL tenotomies in the right foot; and elongation of the transferred TP, TA, and EHL with FHL and FDL tenotomies in the left foot (Table 3).

\section{Discussion}

In Achilles tendon elongation, fractional tenotomy of the gas-

\begin{tabular}{|c|c|c|c|c|c|c|}
\hline Case & Achilles tendon & Tendon transfer & TA transfer & $\begin{array}{l}\text { Anchorage } \\
\text { bone }\end{array}$ & Tendon fixation & $\begin{array}{c}\text { Elongation/Tenotomy } \\
\text { FHL, FDL, FDB }\end{array}$ \\
\hline \multirow[t]{2}{*}{1} & \multirow{2}{*}{$\begin{array}{l}\text { Z-plasty } \\
\text { Z-plasty }\end{array}$} & \multirow{2}{*}{$\begin{array}{l}\text { Tibialis Posterior } \\
\text { Tibialis Posterior }\end{array}$} & \multirow[b]{2}{*}{ - } & Cuboid & Suture anchor & FHL/FDL tenotomy \\
\hline & & & & Cuboid & Suture anchor & FHL/FDL tenotomy \\
\hline 2 & Z-plasty & Tibialis Posterior & - & $3^{\text {rd }}$ Cuneiform & Suture anchor & 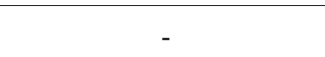 \\
\hline 3 & Z-plasty & Tibialis Posterior & - & $3^{\text {rd }}$ Cuneiform & Suture anchor & FHL/FDL Z-plasty \\
\hline 5 & Fractional-E. & Tibialis Anterior & SPLAT & Cuboid & Suture anchor & FHL/FDB tenotomy \\
\hline 6 & Fractional-E. & Tibialis Anterior & SPLAT & Cuboid & Suture anchor & FHL/FDB tenotomy \\
\hline 7 & Fractional-E. & Tibialis Anterior & SPLAT & Cuboid & Suture anchor & FHL/FDL tenotomy \\
\hline 8 & Fractional-E. & Tibialis Anterior & SPLAT & Cuboid & Suture anchor & FHL/FDL Fractional-E. \\
\hline
\end{tabular}

Table 2: Surgical procedures. 


\begin{tabular}{|c|c|c|c|c|c|c|c|c|}
\hline \multirow[b]{2}{*}{ Case } & \multirow[b]{2}{*}{ Walking ability } & \multicolumn{7}{|c|}{ Surgical procedures and Postoperative problems } \\
\hline & & $\begin{array}{l}\text { Achilles tendon } \\
\text { elongation }\end{array}$ & $\begin{array}{l}\text { Tendon } \\
\text { transfer }\end{array}$ & $\begin{array}{c}\text { Pes } \\
\text { Calaneus }\end{array}$ & Detachment & Revision & Curling toe & Revision \\
\hline \multirow[t]{2}{*}{1} & \multirow[t]{2}{*}{ Nonfunctional } & Z-plasty & $\mathrm{TP}$ & + & & $\begin{array}{l}\text { TP/TA elonga- } \\
\text { tion }\end{array}$ & $\begin{array}{l}\text { FHL/FDL } \\
\text { tenotomy }\end{array}$ & \\
\hline & & Z-plasty & $\mathrm{TP}$ & + & & $\begin{array}{l}\mathrm{TP} / \mathrm{TA} \text { elonga- } \\
\text { tion }\end{array}$ & $\begin{array}{l}\text { FHL/FDL } \\
\text { tenotomy }\end{array}$ & \\
\hline 2 & Household & Z-plasty & $\mathrm{TP}$ & & & & & \\
\hline 4 & Household & Z-plasty & $\mathrm{TP}$ & + & & TP elongation & FHL Z-plasty & \begin{tabular}{|c|} 
FHL \\
Fractional E. \\
FDL Z-plasty
\end{tabular} \\
\hline 5 & Nonfunctional & Fractional-E. & TA & & + & Reattachment & $\begin{array}{l}\text { FHL/FDB } \\
\text { tenotomy }\end{array}$ & \\
\hline 8 & Household & Fractional-E. & TA & & + & Reattachment & $\begin{array}{c}\text { FHL/FDL } \\
\text { Fractional E. }\end{array}$ & $\begin{array}{c}\text { FHL } \\
\text { tenotomy }\end{array}$ \\
\hline 9 & Non-ambulation & Z-plasty & $\mathrm{TA}$ & & & & & \\
\hline 10 & Neighborhood & Z-plasty & $\mathrm{TA}$ & & & & & \\
\hline 11 & Neighborhood & Fractional-E. & $\mathrm{TA}$ & & & & $\begin{array}{c}\text { FHL/FDL } \\
\text { Fractional E. }\end{array}$ & \\
\hline
\end{tabular}

Table 3: Surgical procedures and postoperative problems.

trocnemius is performed to maintain the length of the soleus muscle and minimize the decrease in calf muscle power. On the other hand, Z-plasty shortens the calf muscle and markedly decreases muscle power. Z-plasty may lead to overcorrection of pes calcaneus (calcaneo valgus) when the transferred TP tendon is overactive. Therefore, fractional elongation of the Achilles tendon is recommended to avoid subsequent pes calcaneus (calcaneo valgus) when TP tendon transfer is performed for hindfoot varus deformity. Electromyographic gait analysis shows that the TA is active in these patients with spastic equinovarus, and TA transfer is most often selected for varus correction [10]. In our experience, the TA muscle sometimes becomes functional after Achilles tendon elongation by decreasing the reciprocal inhibition of calf muscle, but the transferred TA muscle contraction is weak and insufficient for toe clearance even if the transfer is sutured under sufficient tension to keep the ankle neutral during the swing phase; thus, ankle foot orthoses are often required [1].

Curling toes were often evident in spastic limbs postoperatively due to tenodynamic action accompanied by ankle dorsiflexion. In
4 feet with toe flexor tendons elongated at the medial ankle, the results were insufficient and three feet required revision surgery. Five feet underwent tenotomies, and the results were all sufficient. Therefore, surgeons should consider performing flexor tenotomy during the initial operation when there is concern for curling toes. Diagnosis in an anesthetized patient is difficult, however, and patients should be informed preoperatively that reoperations may be required for subsequent curling toes.

Following surgery, a short leg cast is applied for 4 weeks, then ankle foot orthoses are applied to protect the transferred tendon reattachment. We experienced 2 patients with detachment of a transferred tendon by the suture anchor system soon after surgery. In those patients, 8 and 11 years had passed since their strokes, respectively, and the anchored bones were osteoporotic. A biomechanical study showed that the suture anchors are superior to conventional bone tunnel fixation in vitro [11], but anchored bones become atrophic over the long-term with insufficient weight bearing in vivo. Therefore, we tried strengthening the reattachment using 
interference screw fixation with tendon-junctional screw system (TJ system) in the last 2 cases. This TJ system for tendon attachment to small bones is strong and is expected to shorten the immobilization period after surgery [12].

Botulinum toxin is effective for spastic equinovarus, but it is insufficient for much more severe spastic deformities accompanied by pain and pressure sores. Achilles tendon elongation after Z-plasty is still useful for extremely severe pes equinus and tarsal fusion might be effective for chronic severe equinovarus deformities [13]. It is important to perform the proper surgical procedures for successful results. Dynamic electromyography is certainly a valuable method for decision-making [10], but it is not yet used generally in clinical practice. We hope surgeons can learn from our successes and failures.

\section{Conclusion}

Achilles tendon elongation following Z-plasty often causes overcorrection of pes calcaneus (calcaneo valgus) when the transferred TP tendon works too strongly. In contrast, overcorrection does not seem to occur when Achilles tendon fractional tendinous elongation and anterior tibial tendon transfer are combined. When flexor elongations for curling toes are performed during the first surgery, multiple subsequent operations are often required. Therefore, surgeons should consider that toe flexor elongations may be insufficient.

\section{Acknowledgement}

The authors deeply thank Kenji Watanabe, MD, PhD for his support.

\section{Conflict of Interest}

The authors have nothing to disclose.

\section{Ethical Approval}

This study was approved by the appropriate ethics review boards at Kameda-Daiichi Hospital.

\section{Bibliography}

1. Waters RL., et al. "Surgical correction of gait abnormalities following stroke". Clinical Orthopaedics and Related Research 131 (1978): 54-63.

2. Renzenbrink GJ., et al. "Improving walking capacity by surgical correction of equinovarus foot deformity in adult patients with stroke or traumatic brain injury: a systemic review". Journal of Rehabilitation Medicine 44 (2012): 614-623.

3. Hosalkar H., et al. "Fixation techniques for split anterior tibialis transfer in spastic equinovarus feet". Clinical Orthopaedics and Related Research 466 (2008): 2500-2506.

4. Yamamoto H., et al. "Surgical correction of foot deformities after stroke". Clinical Orthopaedics and Related Research 282 (1992): 213-218.

5. Brunnstrom S. "Motor testing procedures in hemiplegia: based on sequential recovery stages". Physical Therapy 46 (1966): 357-375.

6. Viosca E., et al. "Proposal and validation of a new functional ambulation classification scale for clinical use". Archives of Physical Medicine and Rehabilitation 86 (2005): 1234-1238.

7. Haga N. "Corrective surgery for equinus". NEW OS NOW 16, TOKYO: Medical View (2002): 46-51.

8. Mitsuhasi T and Otokoto M. "Surgery for spastic equinovarus". NEW OS NOW 16, TOKYO: Medical View (2002): 162-168.

9. Gasse N., et al. "Fixation of split anterior tibialis tendon transfer by anchorage to the base of the 5th metatarsal bone". Orthopaedics and Traumatology, Surgery and Research 98 (2012): 829-833.

10. Walter RL., et al. "Electromyographic gait analysis before and after operative treatment for hemiplegic equinus and equinovarus deformity". The Journal of Bone and Joint Surgery. American Volume 64-A (1982): 284-288. 
11. Fennell CW., et al. "Comparative evaluation of bone suture anchor to bone tunnel fixation of tibialis anterior tendon in cadaveric cuboid bone: biomechanical investigation". Foot and Ankle International 16 (1995): 641-645.

12. Okuno H., et al. "Evaluation of an interference screw for tendon reattachment to small bones". Journal of Orthopaedic Trauma 16 (2002): 418-421.

13. Nonnekes J., et al. "Tarsal fusion for pes equinovarus deformity improves gait capacity in chronic stroke patients". Journal of Neuroengineering and Rehabilitation 16 (2019): 102-107.

\section{Assets from publication with us}

- Prompt Acknowledgement after receiving the article

- Thorough Double blinded peer review

- Rapid Publication

- Issue of Publication Certificate

- High visibility of your Published work

Website: $\underline{w w w}$.actascientific.com/

Submit Article: www.actascientific.com/submission.php

Email us: editor@actascientific.com

Contact us: +919182824667 